\title{
PENERAPAN METODE WEIGHTED PRODUCT UNTUK MENGANALISIS FAKTOR PEMILIHAN PEMBAYARAN DIGITAL TRANSACTION PADA APLIKASI OJEK ONLINE
}

\author{
Ratna Fitria $^{1}$, Syifa Nur Rakhmah ${ }^{2}$ \\ ${ }^{1,2}$ Program Studi Sistem Informasi, STMIK Nusa Mandiri \\ Jl. Damai No.8, Warung Jati (Margasatwa), Jakarta Selatan \\ Telp.(021) 78839513 \\ ${ }^{1}$ Ratnafitria1623@gmail.com, ${ }^{2}$ Syifa.snk@nusamandiri.ac.id
}

\begin{abstract}
This report was conducted to measure the effectiveness of using digital transaction payments on online motorcycle taxis. Where online motorcycle taxi passengers use more digital money than cash as a means of payment. By using criteria on ISO 9001: 2008 factors that influence customer satisfaction include Service Quality, Product Quality, Price, Situational Factor, Personal Factor. This research was conducted on online motorcycle taxi customers in Bekasi regency whose population of 3,500,023 thousand from 23 sub-districts using Slovin calculations found a total sample of 400 respondents. The method used is the weighted product method. The results of this study indicate that the best alternative in digital money is OVO with a value of 0.64 and GO-PAY with a value of 0.36 and for the criteria that attract online motorcycle taxi customers using digital transaction payments, Price with $85 \%$ percentage, Situational 90\% factor, 87\% Personal Factor, $84 \%$ Product Quality and $84 \%$ Service Quality.
\end{abstract}

Keywords: Dicision Support System, ISO 9001:2008, Digital Money, Weighted Product

\section{PENDAHULUAN}

Jasa transportasi online atau yang sering dikenal sebagai taksi dan ojek online dinilai responden sebagai alat transportasi yang lebih murah, cepat dan nyaman. Bahkan, sebanyak 77,6 persen atau lebih dari $3 / 4$ responden mengaku keberadaan ojek dan taksi online ini dapat mengurangi kemacetan, terutama di daerah Jabodetabek yang memang terkenal dengan kemacetannya. Perusahaan-perusahaan yang bergerak dibidang teknologi ini terus berinovasi hingga sekarang menghadirkan berbagai macam layanan yang mampu mengubah hidup banyak masyarakat, khususnya di Indonesia. Sementara itu, terkait metode pembayaran, kurang dari 5 persen dari responden yang menggunakan kartu kredit sebagai alat pembayaran. Sebanyak 48,8 persen responden lebih memilih membayar jasa transportasi online dengan menggunakan uang tunai, dan 46,8 persen mengunakan digital payment dari aplikasi ojek online tersebut (Go-pay maupun GrabPay).

Melihat sedikitnya presentase alat pembayaran dengan menggunakan digital payment, hal ini menjadi tantangan untuk perusahaan ojek online sendiri agar mengajak masyarakat untuk meningkatkan aktivitas transaksi non tunai.

Tentunya dengan adanya uang elektronik dapat lebih membantu masyarakat, dimana masyarakat tidak perlu lagi membawa uang cash, masyarakat hanya perlu membawa gadget sudah bisa melakukan pembayaran pada ojek online. Namun disisi lain pembayaran non tunai (digital transaction) menjadi masalah bagi driver dan penumpang ojek online itu sendiri. Menurut driver ojek online (Kusumaningrum, 2017) pencairan uang dari pendapatan yang didapat cukup lama dan dana yang dicairkannya pun minimal 50.000 rupiah, hal seperti ini menjadi masalah bagi driver ojek online saat mereka membutuhkan uang cash tetapi uang yang mereka butuhkan belum cair padahal mereka harus mengisi bahan bakar kendaraan yang mereka kendarai. Bukan hanya itu saja, dikatakan dalam situs nextren.com (Subyanto, 2018) bahwa wartawan tribunsumsel menemukan modus pemotongan saldo pada aplikasi pembayaran digital yang dilakukan oleh oknum driver ojek online. Hal ini membuat kekhawatiran bagi para pelanggan ojek online yang menggunakan pembayaran digital transaction.

Dari uraian permasalahan yang telah dijabarkan diatas peneliti bermaksud untuk melakukan penelitian untuk menunjang sistem pendukung keputusan terhadap efektifitas penggunaan pembayaran digital transaction pada ojek online sehingga dapat diketahui pengaruh yang dirasakan oleh penumpang ojek online. Penelitian yang dilakukan menggunakan metode Weight Product, pemilihan metode ini didasarkan juga atas kemampuan dalam memberikan solusi optimal dalam pengambilan keputusan. Dari metode Weight Product diharapkan dapat memberikan kesimpulan bahwa adanya pengaruh efektifitas penggunaan pembayaran digital transaction pada ojek online. 


\section{METODE}

Pada penelitian ini melakukan beberapa tahapan yaitu sabagai berikut:

1. Merumuskan masalah

Merumuskan permasalahan pembayaran digital transaction pada ojek online, yaitu apakah faktor yang menyebabkan penumpang ojek online lebih memilih pembayaran dengan digital transaction. Melakukan batasan-batasan permasalahan apa saja yang akan dibahas, serta menentukan kriteria-kriteria apa saja yang akan digunakan dalam penelitian pemilihan pembayaran digital transaction.

2. Mengadakan studi pedahuluan

Mengadakan studi pendahuluan dengan mengumpulkan informasi-informasi yang berkaitan dengan pembayaran digital transaction pada ojek online.

3. Merumuskan hipotesis

Mengemukakan pernyataan awal tentang faktor yang berpengaruh terhadap pemilihan pembayaran digital transaction berdasarkan kriteria yang telah ditentukan. Berikut hipotesis yang penulis tentukan:

$\mathrm{H}_{0} \quad$ : Tidak terdapat pengaruh antara service quality, product quality, price, situational factor, dan personal factor pada minat masyarakat menggunakan pembayaran digital transaction.

$\mathrm{H}_{1} \quad$ : Adanya pengaruh antara service quality, product quality, price, situational factor, dan personal factor pada minat masyarakat menggunakan pembayaran digital transaction.

4. Pengumpulan Data

a) Menentukan sampel penelitian

Menentukan sampel penelitian dengan menggunakan rumus slovin . Jumlah populasi yang diambil dari masyarakat Kabupaten Bekasi yaitu sebanyak 3.500.023 ribu jiwa dengan tingkat eror 5 persen sehingga didapatkan hasil sebagai berikut:

$\mathrm{n}=\mathrm{N} /\left(1+\mathrm{N} .(\mathrm{e})^{2}\right)$

$\mathrm{n}=3.500 .023 /\left(1+3.500 .023 .(5 \%)^{2}\right)$

$\mathrm{n}=3.500 .023 /(1+3.500 .023 .(0,0025))$

$\mathrm{n}=3.500 .023 /(1+3.500 .023 .(0,0025))$

$\mathrm{n}=3.500 .023 / 8.751,05$

$\mathrm{n}=399,95$ atau dibulatkan menjadi 400 sampel

b) Membuat Instrument

Membuat kuesioner yang akan disebarkan kepada masayarakat Kabupaten Bekasi yang jumlah populasinya sebanyak 3.500.023 ribu jiwa.

c) Menguji Instrument

Pengujian instrument dilakukan dengan menguji validitas dan reliabilitas pada kuesioner yang telah diisi oleh responden. Pengujian validitas dilakukan dengan menggunakan rumus korelasi Pearson's Product Moment yang dimana jika $\mathrm{r}_{\text {hitung }}>$ $\mathrm{r}_{\text {tabel }}$ maka instrument tersebut dinyatakan valid, tetapi sebaliknya jika $r_{\text {hitung }}<r_{\text {tabel }}$ maka instrument tersebut dinyatakan tidak valid dan tidak dapat digunakan dalam penelitian. Pengujian relialitas ditentukan dengan koefisien Cronbach Alpha, jika koefisien Cronbach Alpha diatas 0,60 maka instrument tersebut dinyatakan reliabel tetapi jika hasil dari Cronbach Alpha kurang dari 0,60 maka dinyatakan tidak reliabel.

5. Analisis Data

Pengujian hipotesis dilakukan dengan menggunakan metode Weighted Product sehingga dapat diketahui hasil dari pada pengujian tersebut dapat diterima tidak atau tidak, dan dapat diketahui alternatif terbaik dari pembayaran digital transaction pada ojek online.

6. Kesimpulan dan Saran

Menyajikan hasil laporan penelitian sehingga menghasilkan kesimpulan dan saran.

\section{PEMBAHASAN}

\section{1) Penentuan Pembobotan Kriteria}

Pada tahap ini penulis telah menentukan kriteria yang dijadikan acuan dalam perhitungan metode Weighted Product Berikut kriteria yang dimaksud:

Tabel 1. Kriteria

\begin{tabular}{cc}
\hline Kriteria & Kode Kriteria \\
\hline Service Quality & $\mathrm{K}_{1}$ \\
Product Quality & $\mathrm{K}_{2}$ \\
Price & $\mathrm{K}_{3}$ \\
Situational Factor & $\mathrm{K}_{4}$ \\
Personal Factor & $\mathrm{K}_{5}$ \\
\hline
\end{tabular}

Sumber: Peneliti (2019)

Masing-masing kriteria pada kuesioner terdapat 5 (lima) tingkat kepentingan yaitu sebagai berikut:

Tabel 2. Tingkat Kepentingan

\begin{tabular}{cc}
\hline Tingkat Kepentingan & Bobot \\
\hline Sangat Setuju (SS) & 5 \\
Setuju (S) & 4 \\
Netral (N) & 3 \\
Tidak Setuju (TS) & 2 \\
Sangat Tidak Setuju (STS) & 1 \\
\hline
\end{tabular}

Sumber: Peneliti (2019)

Didapatkan nilai bobot untuk setiap kriteria sebagai berikut: 
Tabel 3. Nilai Bobot maksimum

\begin{tabular}{ccc}
\hline Kriteria & Nilai Bobot & Tingkat Kepentingan \\
\hline $\mathrm{K}_{1}$ & 1 & Sangat Tidak Setuju \\
$\mathrm{K}_{2}$ & 2 & Tidak Setuju \\
$\mathrm{K}_{3}$ & 5 & Sangat Setuju \\
$\mathrm{K}_{4}$ & 4 & Setuju \\
$\mathrm{K}_{5}$ & 3 & Netral
\end{tabular}

Sumber: Peneliti (2019)

Kemudian dilakukan perbaikan bobot sehingga $\sum \mathrm{w}$ $=1$ dengan rumus :

$W j=\frac{W j}{\Sigma W \mathrm{j}}$

Keterangan:

$\mathrm{Wj} \quad=$ bobot atribut

$\sum w j=$ penjumlahan bobot atribut

Diperoleh:

$$
\text { a) } \begin{aligned}
\mathrm{W}_{1} & =\frac{3}{3+4+4+2+5} \\
& =\frac{3}{18} \\
& =0,17 \\
\text { b) } \mathrm{W}_{2} & =\frac{4}{3+4+4+2+5} \\
& =\frac{4}{18} \\
& =0,22 \\
\mathrm{~W}_{3} & =\frac{4}{3+4+4+2+5} \\
& =\frac{4}{18} \\
& =0,22 \\
\mathrm{~W}_{4} & =\frac{2}{3+4+4+2+5} \\
& =\frac{2}{18} \\
& =0,11 \\
\mathrm{~W}_{5} & =\frac{5}{3+4+4+2+5} \\
& =\frac{5}{18} \\
& =0,28
\end{aligned}
$$

Sehingga

$\sum \mathrm{W}=0,17+0,22+0,22+0,11+0,28=1$

Keterangan:

$\mathrm{W}_{1}=\mathrm{K}_{1}$

$\mathrm{W}_{2}=\mathrm{K}_{2}$

$\mathrm{W}_{3} \quad=\mathrm{K}_{3}$

$\mathrm{W}_{4} \quad=\mathrm{K}_{4}$

$\mathrm{W}_{5} \quad=\mathrm{K}_{5}$

Berikut merupakan hasil dari perbaikan bobot pada setiap kriteria:

Tabel 4. Hasil Bobot Minimum

\begin{tabular}{cc}
\hline Kode kriteria & Nilai bobot \\
\hline $\mathrm{K}_{1}$ & 0,17 \\
$\mathrm{~K}_{2}$ & 0,22 \\
$\mathrm{~K}_{3}$ & 0,22 \\
$\mathrm{~K}_{4}$ & 0,11 \\
$\mathrm{~K}_{5}$ & 0,28 \\
\hline
\end{tabular}

Sumber: Peneliti (2019)

\section{Menentukan Penilaian dari Setiap Alternatif}

Pada tahap ini penulis telah menentukan alternatif yang dijadikan pilihan dalam memilih pembayaran dengan menggunakan uang digital pada ojek online. Berikut alternatif yang dimaksud:

Tabel 5. Alternatif

\begin{tabular}{ll}
\hline Alternatif & Kode alternatif \\
\hline OVO & $\mathrm{A}_{1}$ \\
GO-PAY & $\mathrm{A}_{2}$ \\
\hline
\end{tabular}

Berdasarkan hasil tabel perhitungan skala likert, OVO dan GO-PAY memiliki hasil nilai untuk masing-masing kriteria, yaitu sebagai berikut:

Tabel 6. Nilai Alternatif

\begin{tabular}{lcccccc}
\hline \multirow{2}{*}{ No } & $\begin{array}{c}\text { Altern } \\
\text { atif }\end{array}$ & \multicolumn{5}{c}{ Kriteria } \\
\cline { 3 - 7 } & $\mathrm{A}_{1}$ & 3081 & 3030 & 3145 & 3076 & $\begin{array}{c}302 \\
5\end{array}$ \\
& & & & & & K3 \\
2 & $\mathrm{~A}_{2}$ & 1761 & 1754 & 1769 & 1764 & $\begin{array}{c}175 \\
4\end{array}$ \\
\hline
\end{tabular}

Sumber: Peneliti (2019)

\section{Menentukan Vektor S}

Dengan cara mengalikan seluruh kriteria bagi sebuah alternatif dengan bobot sebagai pangkat positif untuk kriteria benefit dan bobot berfungsi sebagai pangkat negatif pada kriteria cost. Rumus untuk menghitung nilai preferensi untuk alternatif $\mathrm{S}_{\mathrm{i}}$, diberikan sebagai berikut:

$$
S_{i}=\prod_{j=1}^{n} x_{i j}{ }^{w j}
$$

Keterangan:

$\mathrm{S} \quad$ : menyatakan preferensi alternatif yang dianalogikan sebagai vektor $\mathrm{S}$

: menyatakan nilai kriteria

: menyatakan bobot kriteria

: menyatakan alternatif

: menyatakan kriteria

: menyatakan banyaknya kriteria

1. Menghitung nilai maksimum vektor $\mathrm{S}$

$$
\begin{aligned}
\mathrm{S}_{1} & =\left(3081^{0,07}\right)\left(3030^{0,13}\right)\left(3145^{0,33}\right)\left(3076^{0,27}\right) \\
& \left(3025^{0,20}\right) \\
& =1,75 \times 2,83 \times 14,26 \times 8,74 \times 4,97 \\
& =3.067,69 \\
& =\left(1761^{0,07}\right)\left(1754^{0,13}\right)\left(1769^{0,33}\right)\left(1764^{0,27}\right) \\
\mathrm{S}_{2} \quad & \left(1754^{0,20}\right) \\
& =1,69 \times 2,64 \times 11,80 \times 7,52 \times 4,45 \\
& =1761,78
\end{aligned}
$$

2. Menghitung nilai minimum vektor $S$

$$
\mathrm{S}_{1}=\left(3081^{0,17}\right)\left(3030^{0,22}\right)\left(3145^{0,22}\right)\left(3076^{0,11}\right)
$$




$$
\begin{aligned}
& =3,92 \times 5,83 \times 5,88 \times 2,42 \times 9,43 \\
& =3066,61
\end{aligned}
$$

$$
\begin{aligned}
\mathrm{S}_{2} & =\left(1761^{0,17}\right)\left(1754^{0,22}\right)\left(1769^{0,22}\right)\left(1764^{0,11}\right) \\
& \left(1754^{0,28}\right) \\
& =3,56 \times 5,17 \times 5,18 \times 2,27 \times 8,10 \\
& =1752,99
\end{aligned}
$$

Keterangan:

$\mathrm{S}_{1}=\mathrm{A}_{1}$

$S_{2}=A_{2}$

Berikut merupakan hasil dari perhitungan vektor $\mathrm{S}$ :

Tabel 7. Nilai Maksimum Vektor S

\begin{tabular}{cc}
\hline Alternatif & Nilai Vektor S \\
\hline $\mathrm{A}_{1}$ & $3.067,69$ \\
$\mathrm{~A}_{2}$ & $1.761,78$
\end{tabular}

Sumber: Peneliti (2019)

Tabel 8. Nilai Minimum Vektor $S$

\begin{tabular}{cc}
\hline Alternatif & Nilai Vektor S \\
\hline $\mathrm{A}_{1}$ & $3.066,61$ \\
$\mathrm{~A}_{2}$ & $1.752,99$ \\
\hline
\end{tabular}

Sumber: Peneliti (2019)

\section{Menentukan Vektor V}

Nilai yang akan digunakan untuk perangkingan. Nilai preferensi relatif dari setiap alternatif dapat dihitung dengan rumus:

$$
V_{i}=\frac{\prod_{j=1}^{n} x_{i j}{ }^{w j}}{\prod_{j=1}^{n}\left(x_{j}\right)^{w j}}
$$

Keterangan:

$$
\begin{aligned}
& \mathrm{V}: \text { menyatakan preferensi alternatif yang } \\
& \quad \text { dianalogikan sebagai vektor } \mathrm{V} \\
& \mathrm{x}: \text { menyatakan nilai kriteria } \\
& \mathrm{w}: \text { menyatakan bobot kriteria } \\
& \mathrm{i}: \text { menyatakan alternatif } \\
& \mathrm{j}: \text { menyatakan kriteria } \\
& \mathrm{n}: \text { menyatakan banyaknya kriteria }
\end{aligned}
$$

1. Menghitung nilai maksimum vektor $\mathrm{V}$

$$
\begin{aligned}
\mathrm{V}_{1} & =\frac{3.067,69}{(3.067,69+1.761,78)} \\
& =\frac{3.067,69}{4.829,47} \\
& =0,64 \\
\mathrm{~V}_{2} & =\frac{1.761,78}{(3.067,69+1.761,78)} \\
& =\frac{1.761,78}{4.829,47} \\
& =0,36
\end{aligned}
$$

2. Menghitung nilai minimum vektor $\mathrm{V}$

$$
\begin{aligned}
\mathrm{V}_{1} & =\frac{3.066,61}{(3.066,61+1.752,99)} \\
& =\frac{3.066,61}{4.819,6} \\
& =0,64 \\
\mathrm{~V}_{2} & \frac{1.752,99}{(3.066,61+1.752,99)}
\end{aligned}
$$

$$
\begin{array}{r}
\quad=\frac{1.752,99}{4.819,6} \\
=0,36 \\
\text { Keterangan: } \\
\mathrm{V}_{1}=\mathrm{A}_{1} \\
\mathrm{~V}_{2} \quad=\mathrm{A}_{2}
\end{array}
$$

Berikut merupakan hasil dari perhitungan vektor $\mathrm{V}$ :

Tabel 9. Nilai Maksimum Vektor V

\begin{tabular}{cc}
\hline Alternatif & Nilai Vektor V \\
\hline $\mathrm{A}_{1}$ & 0,64 \\
$\mathrm{~A}_{2}$ & 0,36 \\
\hline
\end{tabular}

Sumber: Peneliti (2019)

Tabel 10. Nilai Minimum Vektor $V$

\begin{tabular}{cc}
\hline Alternatif & Nilai Vektor V \\
\hline $\mathrm{A}_{1}$ & 0,64 \\
$\mathrm{~A}_{2}$ & 0,36 \\
\hline
\end{tabular}

Sumber: Peneliti (2019)

Berdasarkan hasil perhitungan vektor V diketahui bahwa nilai maksimum dan minimum pada vektor $\mathrm{V}$ memiliki nilai yang sama. Sehingga yang menjadi Alternatif tertinggi adalah $V_{1}$ atau OVO dengan nilai 0,64 dan $V_{2}$ atau GO-PAY memiliki nilai 0,36 . Sehingga $V_{1}$ atau OVO adalah alternatif yang terpilih sebagai alternatif terbaik dengan nilai tertinggi.

\section{KESIMPULAN}

Berdasarkan hasil penelitian yang telah ditentukan, maka dapat diperoleh kesimpulan sebagai berikut:

Untuk proses pemilihan pembayaran digital transaction pada ojek online dibutuhkan beberapa kriteria untuk mengukur efektifitas penggunaan digital transaction maka penulis memilih kriteria pada ISO 9001: 2008 faktor yang mempengaruhi kepuasan pelanggan diantaranya yaitu Service Quality, Product Quality, Price, Situational Factor, Personal Factor.

Dari nilai maksimum diketahui bahwa faktor tertingi yang menjadi daya tarik pelanggan ojek online dalam memilih pembayaran digital transaction yaitu Price dengan presentase $100 \%$, Service Quality 84\%, Product Quality 85\%, Situational Factor 90\%, Personal Factor $87 \%$.

Sedangkan untuk nilai minimum menunjukkan faktor yang tidak menjadi daya tarik pelanggan ojek online dalam menggunakan pembayaran digital transaction yaitu Personal Factor dengan presentase 4\%, Service Quality 2\%, Product Quality 3\%, Price 3\%, Situational Factor $1 \%$.

Dari kriteria yang telah ditentukan peneliti kemudian dihitung dengan menggunakan metode Weight Product. Hasil perhitungan yang telah didapatkan dari metode tesebut menunjukkan 
bahwa nilai maksimum dan minimum memiliki hasil yang sama sehingga ranking tertinggi vektor $\mathrm{V}$ adalah OVO dengan nilai vektor 0,64 sedangkan GO-PAY 0,36. Hasil pada pengujian hipotesis menunjukkan bahwa hipotesis $\mathrm{H} 1$ dapat diterima karena menunjukkan hasil yang sesuai dengan penelitian.

\section{PUSTAKA}

Andini, mutia ira. (2018). Penerapan Perkembangan Tik dalam Transportasi "Online." Retrieved from transportasi website:

https://www.kompasiana.com/apradell045608 /5b4e299a6ddcae64c7258282/penerapanperkembangan-tik-dalam-transportasionline?page $=$ all

Arini, N. (2018). Sering Membandingkan Harga Transportasi Online? Aplikasi Ini Akan Memudahkan Penggunanya. Retrieved from https://www.shopback.co.id/blog/transportasi -online-makin-digemari

Ar-Robi, M. R., \& Wibawa, B. M. (2019). Analisis Tingkat Kepuasan dan Performa pada. Jurnal Sains Dan Seni, 8(1), 27-31.

Basri. (2017). Metode Weightd Product (Wp) Dalam Sistem Pendukung Keputusan Penerimaan Beasiswa Prestasi. Jurnal INSYPRO (Information System and Processing), 1-6. https://doi.org/https://doi.org/10.24252/insypr o.v2i1.2474.g2610

Cara, M. (2018). sejarah awal berdirinya gojek hingga jadi ojol terbesar. Retrieved from http://mangcara.com/sejarah-awal-berdirinyagojek-hingga-jadi-ojol-terbesar/

Cermati. (2019a). GOPAY. Retrieved from cermati.com website: https://www.cermati.com/e-money/gopay

Cermati. (2019b). OVO. Retrieved from cermati.com website: https://www.cermati.com/e-money/ovo

De.craft. (2018). Sejarah dan perkembangan ojek di Indonesia. Retrieved from https://www.kaskus.co.id/thread/5ad5ca2ddd d7702a2e8b4568/sejarah-dan-perkembanganojek-di-indonesia/

Elppas. (2017). Apa Itu Grab? Retrieved from https://www.elppas.com/2017/11/apa-itugrab-ini-penjelasan-mudahnya.html

Fahmi, I. (2016). teori dan teknik pengambilan keputusan (Muslim A.Djalil, Ed.). PT RAJAGRAFINDO PERSADA.

Hidayat, A. (2017). Cara Hitung Rumus Slovin Besar Sampel. Retrieved from https://www.statistikian.com/2017/12/hitungrumus-slovin-sampel.html
Hidayat, C. R., Mufizar, T., \& Ramdani, M. D. (2018). Implementasi Metode Weighted Product Pada Sistem Pendukung Keputusan Seleksi Calon Karyawan Bpjs Kesehatan Tasikmalaya. Konferensi Nasional Sistem Informasi 2018, 530-541.

Huwaydi, Y., \& Persada, S. F. (2018). Analisis Deskriptif Pengguna Go-Pay di Surabaya. Jurnal Teknik ITS, 7(1), A55-59. https://doi.org/10.12962/j23373539.v7i1.288 27

Khairina, D. M., Ivando, D., \& Maharani, S. (2016). Implementasi Metode Weighted Product Untuk Aplikasi Pemilihan Smartphone Android. 8(1), 16-23.

Kusumaningrum, D. (2017). Ini Alasan Pembayaran Nontunai Jadi Masalah untuk Pengemudi. Retrieved from digital economy website:

https://www.wartaekonomi.co.id/read147214/ ini-alasan-pembayaran-nontunai-jadimasalah-untuk-pengemudi.html

Marlina, F. (2019). Grab Perusahaan Paling Inovatif Kedua di Dunia. Retrieved from http://finansial.klikpositif.com/baca/46793/grab-perusahaan-paling-inovatif-kedua-didunia

Mirawati, Hikmah, A. B., \& Wiguna, W. (2018). Sistem Penunjang Keputusan Penilaian Kinerja Kasir Lotte Mart Menggunakan Metode Weighted Product. IJCIT (Indonesian Journal on Computer and Information Technology), 3(2), 186-196.

Nofriansyah, D., \& Defit, S. (2017). multi criteria decision making (MCDM) pada sistem pendukung keputusan. Yogyakarta: Deepublish.

Prasetyo, B., \& Jannah, lina miftahul. (2016). metode penelitian kuantitatif. DEPOK: PT RAJAGRAFINDO PERSADA.

Priambodo, S., \& Prabawani, B. (2016). PENGARUH PERSEPSI MANFAAT, PERSEPSI KEMUDAHAN PENGGUNAAN, DAN PERSEPSI RISIKO TERHADAP MINAT MENGGUNAKAN LAYANAN UANG ELEKTRONIK ( Studi Kasus pada Masyarakat di Kota Semarang ). Jurnal Administrasi Bisnis (JAB), 5(2), 1-9.

Purnomo, I. R. S. D., Serfiyani, C. Y., \& Hariyani, I. (2012). Untung dengan Kartu Kredit, Kartu ATM-Debit, dan Uang Elektronik (Z. Simatur, Ed.). Jakarta Selatan: Visi media pustaka.

Rangkuti, F. (2013). customer service satisfaction \& call center berdasarkan ISO 9001. PT Gramedia Pustaka Utama.

Sari, F. (2017). metode dalam pengambilan 
keputusan. Yogyakarta: Deepublish.

Serfiani, C. Y., Purnomo, I. R. S. D., \& Hariyani, I. (2013). Bisnis Online dan Trsansaksi Eektronik. Jakarta: PT Gramedia Pustaka Utama.

Siregar, S. (2016). Statistika Deskriptif Untuk Penelitian. DEPOK: PT RAJAGRAFINDO PERSADA.

Siyoto, S., \& Sodik, M. A. (2015). Dasar Metodologi Penelitian. In $\square \square \quad \square \square \square \square \square$ (Vol. 6). Yogyakarta: literasi media.

Subyanto, W. (2018). Waspada, Driver Online Nakal Bisa Potong Saldo OVO Diam-diam. Retrieved from https://nextren.grid.id/read/011266925/waspa da-driver-online-nakal-bisa-potong-saldoovo-diam-diam?page $=$ all

Sudaryono. (2017). Metodologi Penelitian. DEPOK: PT RAJAGRAFINDO PERSADA.

Sugiyono. (2017a). Metode Penelitian Kuantitatif, kualitatif dan $R \& D$. ALFABETA.

Sugiyono. (2017b). statistika untuk penelitian (D. E. Mulyatiningsih, Ed.). cv alfabeta.

Suryeni, E., Agustin, Y. H., \& Nurfitria, Y. (2015). Sistem Pendukung Keputusan Kelayakan Penerimaan Bantuan Beras Miskin Dengan Metode Weighted Product Di Kelurahan Karikil Kecamatan Mangkubumi Kota Tasikmalaya. Konferensi Nasional Sistem \& Informatika 2015, 345-350.

Usman, R. (2017). Karakteristik Uang Elektronik Dalam Sistem Pembayaran. Yuridika, 32(1), 134-163. https://doi.org/10.20473/ydk.v32i1.4431

Wibowo, S. F., Rosmauli, D., \& Suhud, U. (2015). PENGARUH PERSEPSI MANFAAT, PERSEPSI KEMUDAHAN, FITUR LAYANAN, DAN KEPERCAYAAN TERHADAP MINAT MENGGUNAKAN E-MONEY CARD (STUDI PADA PENGGUNA JASA COMMUTERLINE DI JAKARTA). Jurnal Riset Manajemen Sains Indonesia, 6(1), 440-456. https://doi.org/10.21009/JRMSI.006.1.06 